\title{
Effect of heat pipe failure on performance of residual heat removal system with heat pipe for small lead-based reactor
}

\author{
Chongju $\mathrm{Hu}^{1,2,3, *}$, Hongyan $\mathrm{Wang}^{3}$, Bo $\mathrm{Wu}^{3}$, Xiuxiang Zhang ${ }^{3}$, Pinghua Zhang ${ }^{3}$ \\ ${ }^{1}$ Key Laboratory of Neutronics and Radiation Safety, Institute of Nuclear Energy Safety Technology, HFIPS, Chinese Academy of \\ Sciences, Hefei, Anhui 230031, China \\ ${ }^{2}$ University of Science and Technology of China, Hefei, Anhui 230027, China \\ ${ }^{3}$ Suzhou University, Suzhou, Anhui 234000, China
}

\begin{abstract}
Heat pipe have the characteristics of high thermal conductivity, high safety performance, without external power, etc. In this paper, The numerical simulation CFD software FLUENT is used to study the thermal-hydraulic characteristics performance of heat pipe waste heat removal system with heat pipe for leadbased reactor under normal conditions and Station-Black-Out (SBO) with partial heat pipes damage respectively. Results showed that heat pipes promote heat transfer in the reactor and reduced the temperature of the fluid around the reactor during normal operation; Heat in the core could be removed smoothly by the PRHRS during SBO accident without heat pipe damage ; and when the proportion of failed heat pipes is less than 50\% during SBO accident, the PRHRS could still ensure safe operation of the reactor and the distribution of failed heat pipes in the reactor results the core temperature variation by less than $5 \mathrm{~K}$.
\end{abstract}

\section{Introduction}

The lead-based reactor is an advanced nuclear energy system and chosen as one of the six types of reactors in the fourth generation (Gen-IV) of advanced nuclear energy systems[1]. There are many advantages for the reactor with the lead-based coolant, such as high thermal inertia, high boiling point, high thermal expansion rate, and low kinematic viscosity. Therefore, the lead-based reactor can achieve a large safety margin[2], and the lead-based reactor is expected to be the first industrially demonstrated Gen-IV type of reactor[3].

The residual heat removal system (RHRS) is very important for reactor safety. Once it fails, the reactor core could be melted during accidents. According to the demand of additional power, RHRS can be divided into active residual heat removal system and passive residual heat removal system (PRHRS). During recent years, research of the PRHRS has generated more interest in both the academic and industrial fields worldwidely ${ }^{[4-5]}$. because of its continuous heat removal ability under the Station-Black-Out (SBO) accident ${ }^{[6-7]}$.A heat pipe, as an independent heat transfer unit, has the advantage that limited portion of heat pipes' failure will not affect the normal operation of the whole system. It greatly increases the thermal safety of the reactor during SBO accident. Moreover, it has extraordinary heat transfer capability for non-moving parts, which makes the structure greatly simplified by using heat pipe for heat dissipation[8].

The author's paper in [9] proposed a small lead-based reactor with heat pipes as the PRHRS and studied the thermal-hydraulic performance of the reactor during SBO
accident.However, The above research is based on the premise that all heat pipes work normally, and the partial failure of heat pipes under SBO accident is not considered. In this paper, the temperature characteristics of the heat pipe reactor under normal conditions and Station-BlackOut (SBO) with partial heat pipes damage conditions were studied by using FLUENT, and the influence on core temperature was evaluated when some heat pipes failed.

\section{Reactor and CFD model description ${ }^{[10]}$}

\subsection{Reactor description}

A heat pipe nuclear reactor employing lead-bismuth eutectic (LBE) as a coolant is designed as shown in Fig. 1 . The insulation board divides the reactor into hot pool and cold pool. The hot pool is above the insulation board and the cold pool is below the insulation board. The working fluid of reactor cold pool enters into the core under the action of pump, and then enters into the hot pool after being heated. The heated working fluid is cooled by the primary heat exchangers (PHXs) and then flows back to the cooling pool again. A total of 30 heat pipes are evenly arranged in the reflector. The inlet temperature, outlet temperature and mass flow rate are $683 \mathrm{k}, 722 \mathrm{k}$ and $827 \mathrm{~kg} / \mathrm{s}$, respectively. The thermal power of the reactor is $6 \mathrm{MW}$. The specific parameters of the reactor can be referred to the author's paper [10].

\footnotetext{
*Corresponding author: hucj@mail.ustc.edu.cn
} 


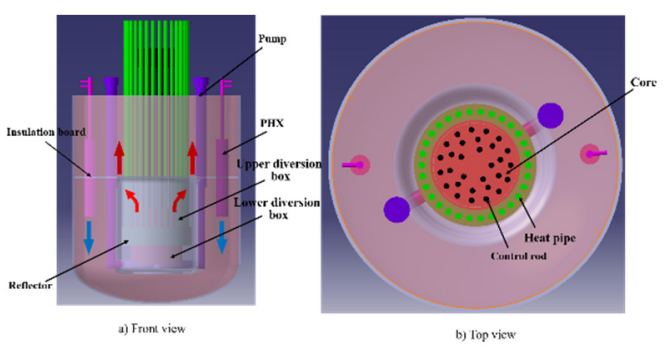

Fig. 1 The LBE reactor design with a heat pipes based PRHRS

\subsection{The CFD model of the LBE reactor}

Considering the calculation cost, the reactor needs to be simplified. Because the control rod does not affect the thermal hydraulic cycle, it is ignored in this CFD model, and the function of pump is replaced by adding momentum source directly to the core. In addition, the PHXs is simplified as porous medium. Fig. 2 shows the CFD model of the LBE reactor.

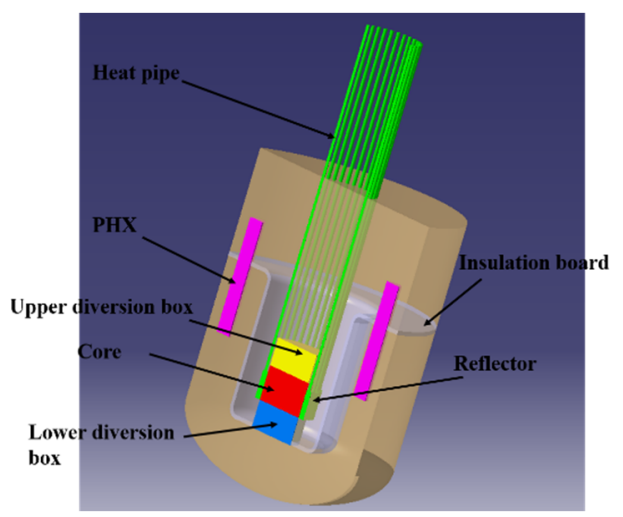

Fig. 2 CFD model of the LBE reactor

\subsection{Boundary conditions}

Because the physical process involves turbulence, the two equation k-epsilon model is used in this study, and the RNG parameters are selected. The radiation boundary condition is used in the condenser of the heat pipe, and the adiabatic boundary condition is used on the outer surface of the whole reactor. All the calculations are based on the conservation of energy, mass, and momentum. The system is considered as steady state. Moreover, the pressure-based steady solver is adopted.

\subsection{Validity of the CFD model}

In order to verify the validity of the CFD model, the results of this calculation are compared with the results of the mature thermal hydraulic relationship[12]. Table 1 shows the comparison of calculation data and CFD data. It can be seen that the maximum relative error between the CFD results and the calculation results of the relationship is $0.5 \%$, which shows that the CFD model in this paper has good prediction ability.

Table 1 Comparison of calculation data and CFD data

\begin{tabular}{llcc}
\hline Parameter & $\begin{array}{l}\text { Calculation } \\
\text { data }\end{array}$ & $\begin{array}{l}\text { CFD } \\
\text { data }\end{array}$ & $\begin{array}{c}\text { Relative } \\
\text { error }\end{array}$ \\
\hline
\end{tabular}

\begin{tabular}{lccc}
\hline $\begin{array}{l}\text { Core inlet } \\
\text { temperature }(\mathrm{K})\end{array}$ & $683 \mathrm{~K}$ & $682 \mathrm{~K}$ & $0.1 \%$ \\
$\begin{array}{l}\text { Core outlet } \\
\text { temperature }(\mathrm{K})\end{array}$ & $733 \mathrm{~K}$ & $732 \mathrm{~K}$ & $0.1 \%$ \\
Mass flow $(\mathrm{kg} / \mathrm{s})$ & $827 \mathrm{~K}$ & $831 \mathrm{~K}$ & $0.5 \%$ \\
\hline
\end{tabular}

\section{Results and discussions}

\subsection{Reactor normal operation analysis}

The velocity and temperature fields of the symmetrical plane for normal operation are shown in Fig. 3 and Fig. 4 From the velocity contours, it can be seen that the LEB from the core outlet flows to the top, then backwards after touching the top, and flows to the cold pool through the PHX. Due to the operation of the main pump, the circulation velocity of LEB in the reactor is so high that the outlet of the PHX does not appear obvious whirlpool, but the LEB directly impacts on the bottom of the reactor vessel. A part of the fluid is returned from the top enters the outside of the diversion box, forming a circulating flow between the diversion box and the heat insulation plate. Having seen from the temperature contours, the temperatures of the hot and cold pools are significantly different on the whole and the temperature of core increases linearly along the flow direction. Moreover, the temperature near the heat pipe is lower than the temperature in the other locations. The result indicates that the heat pipe participates in heat transfer and reduces the surrounding fluid temperature.

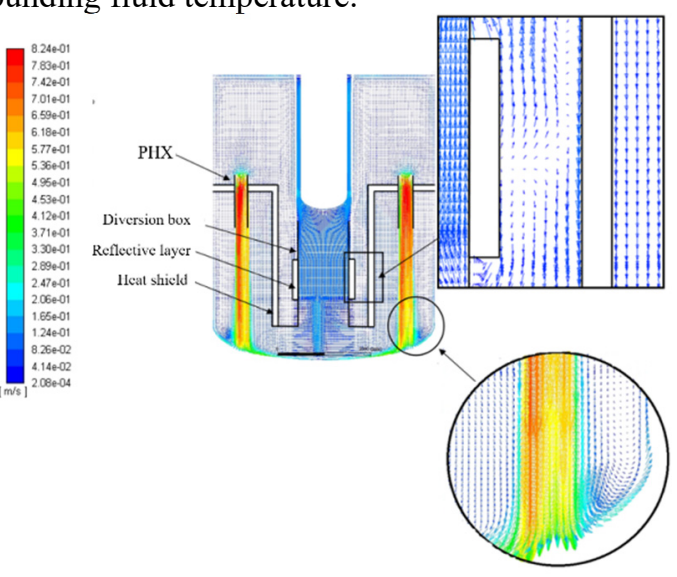

Fig. 3 Velocity distribution of reactor symmetry plane during normal operation

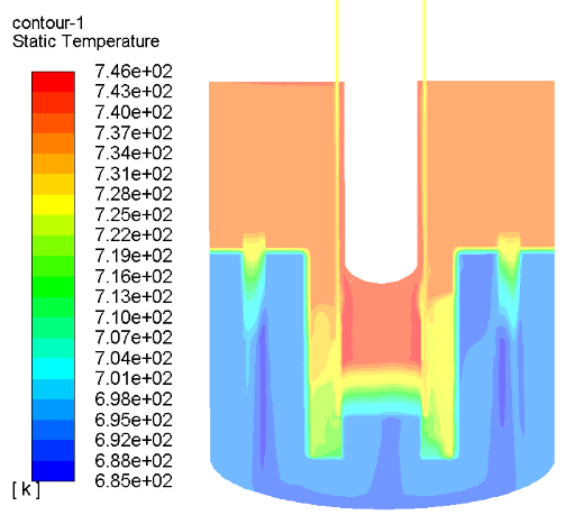

Fig. 4 Temperature distribution of reactor symmetry plane during normal operation 
Fig.5 shows the temperature contour of the reflector and heat pipes, which are rotated clockwise by $90 \mathrm{o}$ for better visualization of the temperature. It is clear that the average temperature difference between the evaporation section and the condensation section of the heat pipe is less than $5 \mathrm{~K}$, which further proves the good heat conduction characteristics of the heat pipe. The temperature of the heat pipe in vapor chamber is high in the middle and low at both ends due to the different temperature distributions of the fluid outside the heat pipe. From the radial direction of the heat pipe, there is a large temperature gradient in the wall thickness of the heat pipe and the wick. The maximum temperature difference can be up to $4 \mathrm{~K}$ in the evaporation section and the condensation section. Hence, it can be concluded that the thermal resistance of the heat pipes mainly occurs in the radial direction and this characteristic of the heat pipes can be used to realize longdistance heat transfer with a low temperature drop.

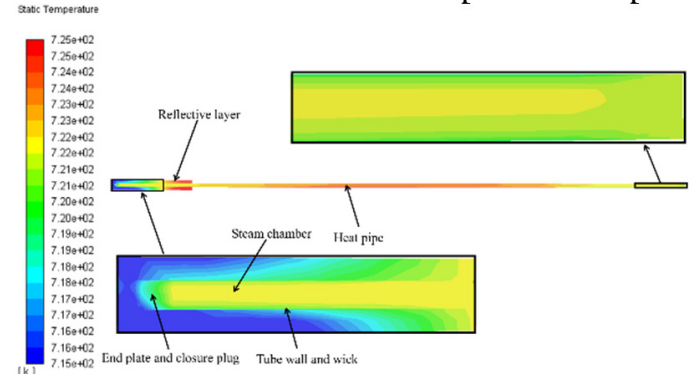

Fig. 5 Temperature distribution of a heat pipe and the reflector during normal operation

Fig. 6 shows the temperature distribution of the reactor core and the temperature rises along the axial direction of the core. The heat absorbed gradually increases as fluid flows through the core. The temperature tends to be the same and only slightly higher at the outermost layer as seen from the radial direction. During the normal operation in the inner layer of the core, most parts of the heat are transferred through the convection but the heat in the outermost layer of the core is transferred to the reflector through the conduction.

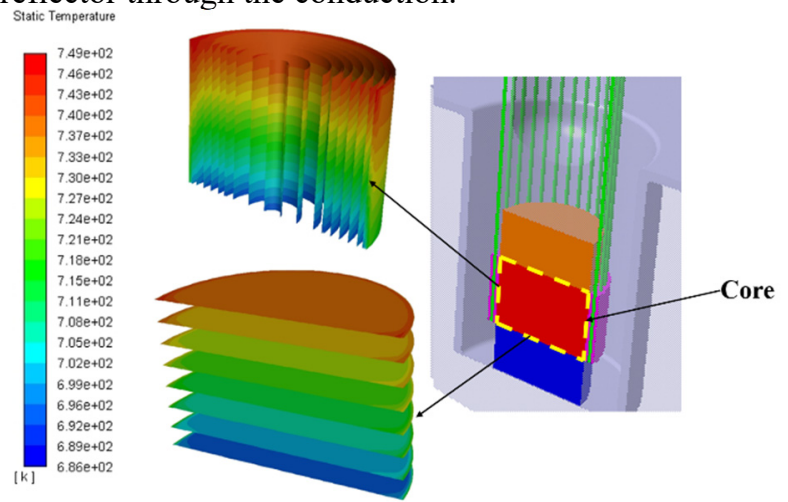

Fig. 6 Temperature distribution of the reactor core during normal operation

\subsection{SBO accident without heat pipe damage}

In order to verify the performance of the heat pipes based PRHRS during SBO accident, the heat sink PHXs were removed, the momentum of the main pump was reduced to zero, and the power of the reactor core is decreased to
$2 \%$ of the normal power for a long term. The main thermal results of the steady-state simulation are listed in Table 2.

Regarding to the maximum temperature of the core, the heat pipes based PRHRS controls the temperature of the reactor in the safe range. During the SBO accident, the mass flow rate of the coolant is $8 \mathrm{~kg} / \mathrm{s}$, it is about $1 \%$ of the normal operation.

Table 2 Simulation results of thermal-hydraulics parameters during SBO accident

\begin{tabular}{lc}
\hline Parameter & CFD results \\
\hline Min. core temperature (K) & 814.4 \\
Max. core temperature (K) & 834.1 \\
Coolant mass flow (kg/s) & 8.0 \\
\hline
\end{tabular}

\subsection{SBO accident with partial heat pipes damage}

\subsubsection{Influence of the number of failed heat pipes}

The effects of partial heat pipe failures on the reactor temperatures were simulated for evaluating the impact of different numbers of adjacent heat pipe damage on the reactor thermal safety during SBO accident. Fig. 7 shows the minimum and maximum temperatures of the core with different numbers of adjacent heat pipe damage conditions. While the number of failed heat pipe increases, the core temperatures will increase, and the temperature-rising rate will increase. It is concluded that the reduction of the heat dissipation area is caused by the damage of the heat pipe, and the temperature difference is increased to ensure the heat dissipation not be changed. While the number of heat pipe failures reaches 15 , the maximum core temperature reaches $1023 \mathrm{~K}$. However, the number of heat pipe failures reaches $50 \%$ in this case, and the likelihood of this happening is remote.

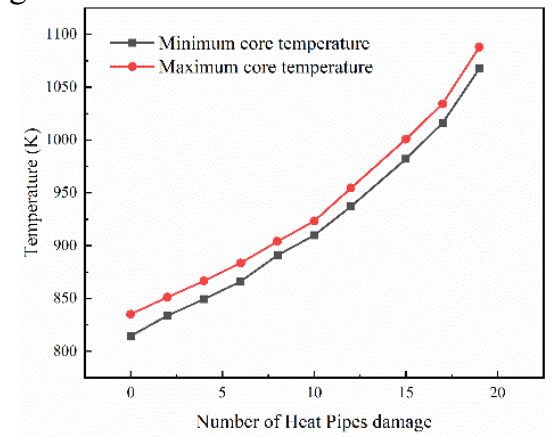

Fig. 7 The reactor core temperature for different damage numbers of heat pipes

\subsubsection{Effects of the distribution of damaged heat pipes}

In order to study the influence of different distributions of the failed heat pipes on the maximum core temperature, five different numbers of the failed heat pipes in total were studied, which are 2, 4, 6, 8, and 10, respectively. For each number of the total failed heat pipes, all the failed pipes are divided into 2 continuous groups with a number $\mathrm{N}$ of the working pipes between. For example, Fig. 14 shows the distributions of the cases that the number of the total failed heat pipes is 2 . Fig. 8(a) shows the number $\mathrm{N}$ of the 
working pipes between 2 continuous failed pipe groups is 1, and Fig. 8(b) shows the number $\mathrm{N}$ of the working pipes is 3. Fig. 9 shows the distributions of the cases that with 4 failed heat pipes likewisely.

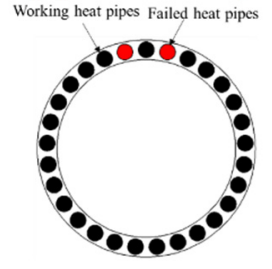

(a)

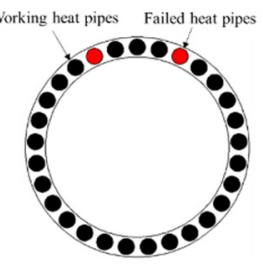

(b)
Fig. 8 Distributions of 2 failed heat pipes: (a) $\mathrm{N}=1$; (b) $\mathrm{N}=3$

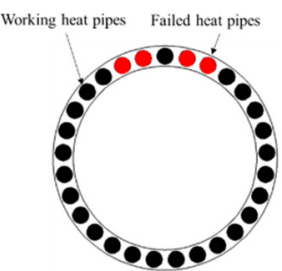

(a)

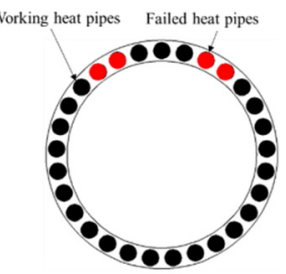

(b)
Fig. 9 Distributions of 4 failed heat pipes: (a) $N=1$; (b) $N=3$

Fig. 10 shows the results of the maximum core temperature variations on the different heat pipes failure distributions. For each case with a certain number of failed heat pipes, the increasing distance of 2 continuous failed pipe groups results in an obvious decreasing maximum core temperature. However, while the distance becomes larger, the variation of the maximum core temperature still remains decreasing but with a smaller decreasing rate. Concerning to the total number of the failed heat pipes, it is found that while only two heat pipes were failed, the maximum core temperature variation is less than $3 \mathrm{~K}$ comparing to the case without any failed heat pipes. While the total number of failed heat pipes reaches 10, the variation of the maximum core temperature reaches up to $5 \mathrm{~K}$.

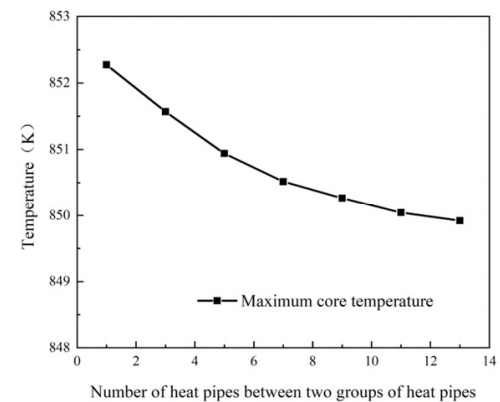

a) 2 failed heat pipes

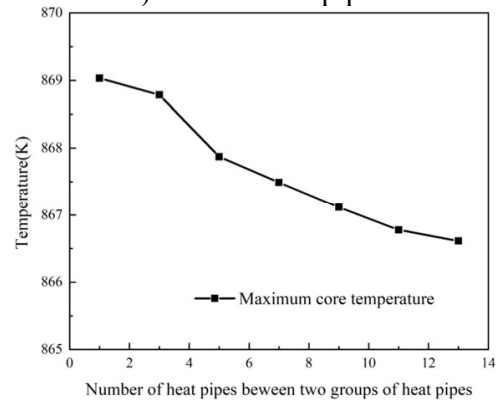

b) 4 failed heat pipes

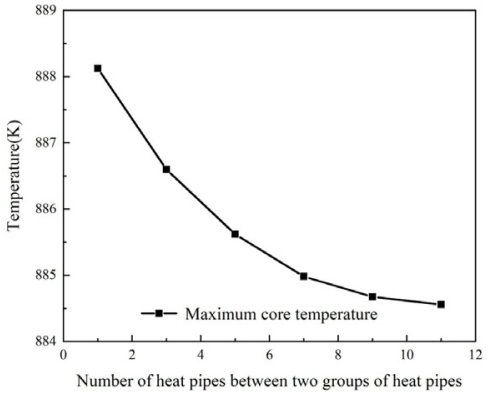

c) 6 failed heat pipes

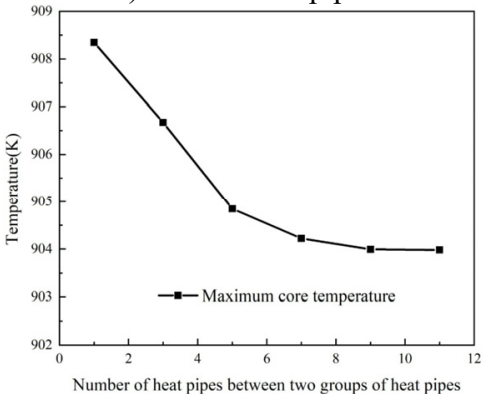

d) 8 failed heat pipes

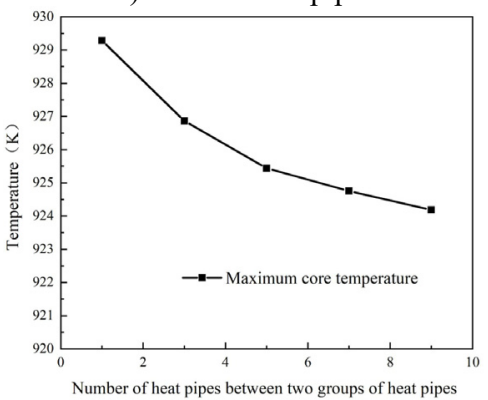

e) 10 failed heat pipes

Fig. 10 Maximum core temperature variations on the different heat pipes failure distributions

\section{Conclusion}

A LBE reactor with a heat pipes based PRHRS was designed, and a three-dimensional numerical simulation model of the reactor was established with reasonable simplification. The distribution of temperature and velocity fields in the reactor with a heat pipes based PRHRS under different operation and accident conditions was analyzed. The main results are summarized as follows:

The nuclear reactor can ensure the safety of the core no matter during the normal operation condition or the SBO accident condition.

The influence of the number of failed heat pipes on the core temperature during the SBO accident was studied. The result shows that the core safety can be well guaranteed even though the number of failed heat pipes reaches $50 \%$ of the total heat pipes, which indicates that the reactor has a very safe margin.

The impacts of the distribution of the failed heat pipes on the core temperature during the SBO accident are studied. Results show that the maximum temperature variation is less than $5 \mathrm{~K}$, which can be disregarded.

\section{Acknowledgments}

This work was supported by the key projects of natural 
science research in Anhui Province (Grant No. KJ2020A0730) ,The teaching Studio (Grant No. 2016msgzs071), The open research platform project of Suzhou University (Grant No. 2020ykf14), The Key projects of Suzhou University (Grant No. 2020yzd08).

\section{References}

1. Kelly J E., 2014. Generation IV International Forum: A decade of progress through international cooperation. Progress in Nuclear Energy. 77, 240-246.

2. Wu Y C, Wang M, Huang Q Y, et al., 2015. Development status and prospects of lead-based reactors. Nuclear Science and Engineering. 35(2), 213-221. (in Chinese)

3. International Atomic Energy Agency., 2003, Power reactors and sub-critical blanket systems with lead and lead-bismuth as coolant and/or target material. IAEA-TECDOC-1348.

4. Achilli A, Cattadori G, Ferri R, et al., 2000. Two new passive safety systems for LWR applications. Nuclear Engineering and Design. 200, 383-396P.

5. Bae K H, Kim H C, Chang M H, et al., 2001. Safety evaluation of the inherent and passive safety features of the smart design. Annals of Nuclear Energy. 28, 333-349.

6. Yamada K., 2012. Lessons learned from the Fukushima accident to apply to water cooled reactor technology development, presented at the International Workshop on Nuclear Safety and Severe Accidents (NUSSA), Beijing, China, September 7-8.

7. Viktorov A., 2012. Enhancing safety of Canadian nuclear power plants Post-Fukushima: Regulatory Assessment, presented at the International Workshop on Nuclear Safety and Severe Accidents(NUSSA), Beijing, China, September 7-8.

8. El-Genk M S, Tournier J M P., 2004. "SAIRS" scalable Amtec integrated reactor space power system. Progress in Nuclear Energy. 45(1), 25-69.

9. James J. Duderstadt, Louis J. Hamilton., 1976. Nuclear Reactor Analysis. John Wiley and Sons, Inc; New

10. Hu C , Huang W, Jiang Z, et al. Analysis on passive residual heat removal system with heat pipes for longterm decay heat removal of small lead-based reactor $[\mathrm{J}]$. E3S Web of Conferences, 2021, 236(3):01018. 